\title{
ANALISIS KEBUTUHAN POS PEMADAM KEBAKARAN BERDASARKAN TINGKAT KERAWANAN KAWASAN DI KABUPATEN PATI
}

\section{NEED ASSESTMENT OF FIRE STATIONS BASED ON HAZARD LEVEL IN PATI REGENCY}

\author{
Agus Sugianto', Imam Buchori' \\ Magister Perencanaan Wilayah dan Kota; Universitas Diponegoro; agus.gfr31@gmail.com; i.buchori@undip.ac.id
}

Info Artikel:

- Artikel Masuk: 16 Agustus 2018

- Artikel diterima: 19 September 2018

- Tersedia Online: 30 Maret 2020

\begin{abstract}
ABSTRAK
Kejadian kebakaran periode 2012-2016 di kabupaten Pati hampir meliputi semua kecamatan yang ada, terjadi di wilayah perkotaan maupun perdesaan. Kerugian material mencapai milyaran rupiah dan korban jiwa. Padahal perlindungan terhadap bahaya kebakaran kabupaten dan kota di Indonesia, merupakan pelayanan dasar dalam penyelenggaraan pemerintahan. Satu pos pemadam kebakaran tidak mampu menjangkau seluruh wilayah, akibatnya kegagalan pemadaman karena terlambat datang. Tujuan dari penelitian ini adalah untuk menganalisis kebutuhan pos pemadam kebakaran berdasarkan tingkat kerawanan kawasan dan perlindungan kawasan strategis di kabupaten Pati. Pemilihan metode kuantitatif dengan pendekatan spasial. Penentuan kerawanan kebakaran kawasan menggunakan analisis spasial multi kriteria dan analisis pairwise comparism (AHP). Selanjutnya menggunakan kriteria eliminator melalui teknik overlay untuk alternatif lokasi. Evaluasi jangkauan pelayanan setiap lokasi dengan Service area pada Network Analyst di Arcgis 10.4 untuk mengetahui jumlah ideal pos pemadam. Hasil penelitian menunjukan tingkat kerawanan kawasan tinggi seluas 5.141 ha (3,42\%), sangat tinggi seluas 68,68 ha $(0,05 \%)$ dari wilayah studi dan tersebar di perkotaan dan perdesaan. Pada tahap elemininasi dan evaluasi lokasi berdasarkan jangkauan layanan pos pemadam menurut time rate 5 menit ada 9 lokasi baru, time rate 10 menit dibutuhkan 8 lokasi. Hasil akhirnya adalah 6 lokasi baru pos pemadam baru jika dikomparasi terhadap kebijakan kawasan dan memperhitungkan area layanan pos eksisting.
\end{abstract}

\section{ABSTRACT}

The fire accidents in a period of 2012 to 2016 in Pati Regency which happened in almost all districts occurred in urban and rural areas. The material loss because of the accident reached billion rupiahs and even, many lives became the victims. This happened while the protection from the fire hazard in Indonesian regencies and cities is the basic service of the national governance. One fire station can not reach the entire areas so that the extinguishing of fire fails as a result of the late arrival of the municipal fire brigade. Therefore, the purpose of this study is to assess the need of fire stations based on the hazard level and on the protection of the strategic areas in Pati Regency. This study uses quantitative method with spatial approach. The determination of the fire hazard uses spatial multi-criteria and pairwise comparison analysis (AHP). Then, the study used eliminator criteria by applying overlay technique to get the alternative locations. The evaluation of service reach of every location from the service area on the Analyst Network in Arcgis 10.4 was conducted to know the ideal number of fire stations needed. The result of the study shows that the hazard level of the areas studied is high in the areas of 5,141 hectares (3.42\%), and very high in 68.68 hectare (0,05\%) areas all over the cities and villages. In the stage of elimination and location evaluation based on the 5-minute time rate of the fire station service reach, there are 9 new locations, while in 10-minute time rate, there are 8 locations needed. The final result is that there will be 6 new locations for new fire stations if they are compared towards the area policy and consider the existing service area

Keyword: Fire, Rural, Urban, Pati

Copyright $\odot 2020$ JPWK-UNDIP This open access article is distributed under a Creative Commons Attribution (CC-BY-NC-SA) 4.0 International license.

\section{PENDAHULUAN}

Kebakaran merupakan salah satu jenis ancaman bencana di Indonesia berdasarkan peraturan kepala PNBP no 2 tahun 2012. Dibandingkan jenis bencana yang lain, korban jiwa sangat kecil akan tetapi harta benda tergolong tinggi (Srivanit, 2011). Ancamanan kebakaran merupakan bahaya tersembunyi (Wei, et. al., 2011), karena terjadi dimana saja dan waktu yang tidak dapat diprediksi. Sebagian besar kejadian merupakan 
hasil dari aktivitas manusia dan sangat kecil kejadian disebabkan faktor alam. Perlindungan keamanan terhadap bahaya kebakaran merupakan pelayanan dasar dalam penyelenggaraan pemerintah daerah pada wilayah perkotaan dan perdesaan (Kementrian Dalam Negeri, 2012), agar pembangunan yang sedang massif dilakukan tidak terganggu. Karena salah satu tantangan pembangunan, khususnya diperkotaan adalah layanan terhadap pemadam kebakaran (Wahab \& Khayyat, 2014). Dampak dari ketidakmampuan mengatasi permasalahan kebakaran dapat mendegradasi kepercayaan kepada pemerintah oleh masyarakat (Song, et. al., 2018). Permasalahan bahaya kebakaran dialami hampir semua kabupaten/ kota di Indonesia, termasuk kabupaten Pati. Berdasarkan data dari Dinas Satuan Polisi Pamong Praja/ Dinas Satpol PP (2017), menunjukkan kejadian kebakaran tahun 2012-2016 mencapai 35-83 kebakaran pertahun, baik itu di permukiman, industri maupun lahan, tersebar di 20 kecamatan yang terjadi di desa perkotaan maupun desa perdesaan. Kerugian selama periode tersebut meliputi korban jiwa dan materi sebesar Rp. 80.555.700.000. Sementara keberadaan pos pemadam kebakaran milik pemerintah hanya ada 1 (satu) lokasi untuk melayani wilayah seluas $1.503,68 \mathrm{~km} 2$. Sebenarnya ada 3 pos milik stakeholder (swasta) yang selama ini membantu penanggulangan kebakaran, akan tetapi belum ada kerjasama formal dengan pemerintah daerah sehingga tidak maksimal peranannya. Bertolak dari permasalahan yang terjadi, maka tujuan dilakukan penelitian ini adalah untuk menganalisis kebutuhan lokasi pos pemadam kebakaran berdasarkan kawasan rawan kebakaran dan perlindungan terhadap kawasan strategis di kabupaten Pati, agar pelayanan setiap pos pemadam kebakaran optimal dan mampu menjangkau lokasi menurut waktu tanggap darurat. Dengan demikian diharapkan dampak kerugian dapat dicegah atau diminimalisir, serta pembangunan membawa kesejahteraan di kabupaten Pati.

Menurut Hardi (2005, dalam Keane, et.al., 2010), Kuantifikasi kebakaran dan risiko sangat penting untuk mengidentifikasi dan memprioritaskan daerah-daerah yang membutuhkan penanganan. Pemetaan potensi kerawanan kebakaran suatu wilayah (Chhetri \& Kayastha, 2015; BNPB, 2012), langkah pertama memperkirakan lokasi maupun waktu kejadian dan resiko kebakaran (Hessburg et. al., 2007 dalam Keane et al., 2010), menjadi salah satu pendekatan melakukan prioritas proteksi terhadap kebakaran adalah pembangunan pos pemadam baru. Penggunaan Analytic Hirarchy Process (AHP) dan Analisis spasial multi kriteria telah banyak dilakukan dalam memetakan potensi kerawanan kebakaran. Dimana penggunaan Sistim Informasi Geografis (SIG) dalam analisis spasial beserta metode pengambilan keputusan, akan menghasilkan efek sinergis yaitu efisiensi dan kualitas spasial (Rikalovic, et. al., 2014). Chhetri \& Kayastha (2015), memetakan kerawanan kebakaran di Kathmandu dengan AHP dan SIG berdasarkan jarak dari SPBU, tata guna lahan dan kepadatan penduduk. Srivanit, ( 2011) melihat kerawanan di Chiangmai dari keberadaan gedung tinggi, fungsi bangunan, kepadatan penduduk, jenis bahan bangunan, aksessibilitas memadam kebakaran dan pusat kegiatan. Termasuk kapasitas mitigasi adalah aksesibilitas jalan, jarak dari pos pemadam, jarak ke hidran, sejarah kebakaran dan jarak ke sumber air. Muryamto (2004) menilai daerah yang rawan bencana kebakaran dari vagetasi pada lahan, jalan, sumber air dan kedekatan dengan properti. Menurut Kementrian Dalam Negeri (2012) dan Kementrian PU (2009), kerawanan sebagai akibat tidak terlindungi suatu area dari jangkauan pos pemadam, adanya jaringan jalan dan kontuinitas pasokan air saat kejadian kebakaran. Keberadaan lokasi pos pemadam yang kurang sesuai dan tanpa perencanaan yang baik akan membuat penanggulangan kebakaran tidak efektif (Bagir \& Buchori, 2012). Oleh karena itu, kebutuhan berdasarkan lokasi permintaan (geodemand) harus menjadi prioritas (Roig-Tierno, et. al., 2013). Menurut Badri, et. al., (1998), pembangunan pos pemadam harus mempertimbangkan moneter, permintaan/ wilayah yang memerlukan layanan, meminimalkan overlay area layanan, kebijakan terhadap wilayah dan ketersedian sumber air. (Habibi,et. al., 2008), menegaskan bahwa kebutuhan pos pemadam harus memperhatikan aksesibilitas, area layanan, populasi penduduk, luas pos pemadam dan regulasi pengembangan kota. Sementara BSN (2004) mensyaratkan pos pemadam merupakan bagian fasilitas publik pengembangan kawasan perkotan dan Kementrian PU (2009) mensyaratkan harus berdasarkan RTRW, area jangkauan dan ketersedian sarana dan prasarana pemadam kebakaran.

Metode penelitian yang digunakan metode kuantitatif dengan pendekatan spasial. Metode ini memiliki karakteristik dimana space dianggap variabel utama. Teknik-teknik analisis kuantitatif mendominasi pada awalnya dan kemudian terjadi penggabungan teknik analisis kuantitatif dan kualitatif (Yunus, 2010:42). 
Teknik analisa menggabungkan analisa spasial multikriteria dan pairwise comparism, dimana pengolahan data menggunakan overlay dan network analyst-service area untuk melihat area layanan pos pemadam. Penelitian ini memiliki wilayah studi tidak hanya perkotaan, akan tetapi melibatkan wilayah perdesaan di kabupaten Pati. Penelitian yang sudah ada hanya melihat kebutuhan perlindungan dari bahaya kebakaran pada wilayah perkotaan dan hutan maupun lahan. Penentuan pos pemadam kebakaran akan dilakukan melalui eliminasi terhadap kedekatan terhadap area bencana, kemudahan aksesibilitas, bagian dari fasilitas perkotaan, tidak berada pada wilayah rawan bencana, tidak berada pada lahan terbangun dan memiliki luas yang dibutuhkan. Hasilnya kemudian ditentukan berdasarkan area layanan menurut waktu tanggap darurat dan kebutuhan proteksi menurut kebijakan strategis kabupaten dalam pengembangan wilayahnya

\section{DATA DAN METODE PENELITIAN}

2.1. Gambaran Wilayah Studi

Wilayah penelitian ini meliputi seluruh wilayah kabupaten Pati, JATENG. Luas Kabupaten Pati 1.503,68 $\mathrm{km}^{2}$. Secara administrasi terdiri dari 21 kecamatan, 401 desa dan 5 kelurahan. Menurut klasifikasi desa ada 107 desa perkotaan dan 299 desa perdesaan.

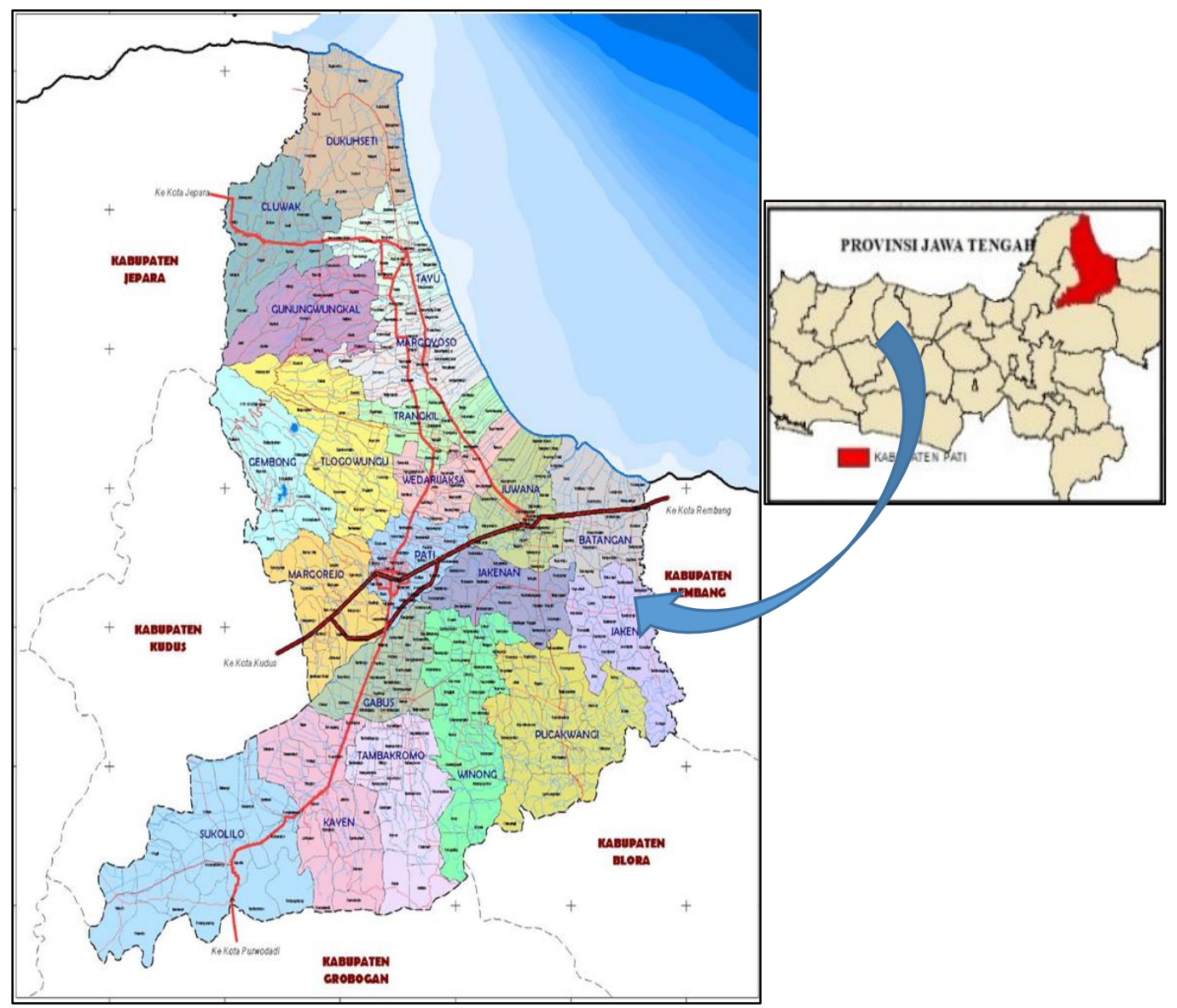

Sumber: RTRW 2010-2030, 2010

Gambar 1. Peta wilayah studi (RTRW 2010-2030, 2010)

\subsection{Data}

Ada 2 (dua) jenis data yang digunakan dalam penelitian ini yaitu data primer dan sekunder. Data primer didapat dari sumber data pertama dilokasi penelitian dan interview terhadap narasumber. Sementara data sekunder dari sumber kedua, seperti instansi terkait meliputi data pemetaan, laporan kebakaran tahun 20122016, buku maupun jurnal yang terkait tema penelitian. 


\subsection{Metode Penelitian}

\subsubsection{Analisis Pairwise Comparism dalam AHP}

Analisis ini merupakan bagian dari analisis yang digunakan dalam menentukan kerawanan kebakaran. Ada tingkatan dalam AHP untuk menentukan tujuan, yaitu kriteria, sub kriteria dan alternatif (Saaty, 2008). Penentuan bobot pengaruh setiap kriteria kerawanan kebakaran digunakan tingkat ke-1 atau menggunakan matrik berpasangan kriteria yang akan digunakan analisis spasial yaitu weighted overlay. Responden dalam penelitian yang diharapkan mampu memberikan gambaran secara komprehensif tentang kerawanan kebakaran meliputi perencana, petugas lapangan, pejabat lokal (Srivanit, 2011).

\subsubsection{Analisis Kerawanan Kebakaran}

Analisis kerawanan kebakaran menggunakan pendekatan Weighted Overlay dalam Arc Gis 10.4 dengan data berbentuk raster, sehingga menghasilkan tingkat kerawanan kebakaran yang tersebar di kabupaten Pati. Selanjut peta ini menjadi rujukan dalam menentukan kebutuhan dan lokasi pos pemadam kebakaran. Berdasarkan tabel 1, dimana kerawanan kebakaran karena adanya kejadian, kepadatan penduduk yang tinggi pada lahan terbangun, berada di luar jangkauan pos pemadam kebakaran, berada di luar jangkauan pelayanan jalan dan keberadaan sumber air. Untuk lebih memahami permasalahan, pemetaan menggunakan metode pairwise comparism dalam AHP untuk mengetahui bobot kriteria pembentuk kerawanan di Kabupaten Pati.

Tabel 1. Skoring Parameter Dalam Analisis Rawan Bencana Kebakaran (Hasil analisis, 2018)

\begin{tabular}{|c|c|c|c|c|c|}
\hline NO & VARIABEL & SKOR & URAIAN & BESARAN & KETERANGAN \\
\hline \multirow[t]{5}{*}{1} & Kepadatan Penduduk Netto & 1 & $\begin{array}{l}\text { Kepadatan penduduk (jiwa/ km2) pada } \\
\text { lahan terbangun }\end{array}$ & $<500$ & Sangat rendah \\
\hline & & 2 & $\begin{array}{l}\text { Kepadatan penduduk (jiwa/ km2) pada } \\
\text { lahan terbangun }\end{array}$ & $500-2.499$ & Rendah \\
\hline & & 3 & $\begin{array}{l}\text { Kepadatan penduduk (jiwa/ km2) pada } \\
\text { lahan terbangun }\end{array}$ & $\begin{array}{c}2.500- \\
5.999\end{array}$ & Sedang \\
\hline & & 4 & $\begin{array}{l}\text { Kepadatan penduduk (jiwa/ km2) pada } \\
\text { lahan terbangun }\end{array}$ & $\begin{array}{l}6.800- \\
8.499\end{array}$ & Tinggi \\
\hline & & 5 & $\begin{array}{l}\text { Kepadatan penduduk (jiwa/ km2) pada } \\
\text { lahan terbangun }\end{array}$ & $>8.500$ & Sangat tinggi \\
\hline \multirow[t]{5}{*}{2} & Frekuensi kejadian kebakaran & 1 & $\begin{array}{l}\text { Kejadian kebakaran pertahun dalam } 5 \\
\text { tahun }\end{array}$ & 0 & Tidak rawan \\
\hline & & 2 & $\begin{array}{l}\text { Kejadian kebakaran pertahun dalam } 5 \\
\text { tahun }\end{array}$ & 1 & Rendah \\
\hline & & 3 & $\begin{array}{l}\text { Kejadian kebakaran pertahun dalam } 5 \\
\text { tahun }\end{array}$ & 2 & Sedang \\
\hline & & 4 & $\begin{array}{l}\text { Kejadian kebakaran pertahun dalam } 5 \\
\text { tahun }\end{array}$ & 3 & Tinggi \\
\hline & & 5 & $\begin{array}{l}\text { Kejadian kebakaran pertahun dalam } 5 \\
\text { tahun }\end{array}$ & 4-5 & Sangat Rawan \\
\hline \multirow[t]{2}{*}{3} & Jangkauan pelayanan pos PMK & 1 & Kawasan berjarak 7,5 km dari pos PMK & $\leq 7,5 \mathrm{~km}$ & Terjangkau \\
\hline & Eksisting & 5 & Kawasan berjarak 7,5 km dari pos PMK & $>7,5 \mathrm{~km}$ & Tidak Terjangkau \\
\hline \multirow[t]{2}{*}{4} & Jangkauan layanan jalan & 1 & Jarak lokasi kebakaran dari jalan & $0-200 \mathrm{~m}$ & Terjangkau \\
\hline & & 5 & Jarak lokasi kebakaran dari jalan & $>200 \mathrm{~m}$ & Tidak terjangkau \\
\hline \multirow[t]{2}{*}{5} & Sumber Air & 1 & $\begin{array}{l}\text { Jarak lokasi kebakaran dari jaringan } \\
\text { sungai }\end{array}$ & $0-50 \mathrm{~m}$ & Terjangkau \\
\hline & & 5 & $\begin{array}{l}\text { Jarak lokasi kebakaran dari jaringan } \\
\text { sungai }\end{array}$ & $>50 \mathrm{~m}$ & Tidak terjangkau \\
\hline
\end{tabular}

Sumber: Hasil analisis, 2018

\subsubsection{Analisis Kebutuhan Lokasi Pos Pemadam}

Ada 2 (dua) tahap dalam penentuan kesesuaian lokasi yaitu tahap penyaringan dan tahap evaluasi(Christo \& Weku, 2012), begitu juga penentuan pos pemadam di kabupaten Pati. Tahap Penyaringan 
menggunakaan variabel eliminator, sedangkan tahap evaluasi lokasi terpilih terhadap area layanan berdasarkan waktu tanggap darurat dan kebijakan pengembangan wilayah yang memerlukan perlindungan terhadap bahaya kebakaran. Tahap penyaringan, merupakan upaya mengeliminasi kandidat lokasi yang tidak sesuai kriteria lokasi karena adanya regulasi atau faktor lainnya menggunakan variabel eliminator seperti yang disajikan dalam tabel 2. Penentuan lokasi pos PMK berbasis analisis spasial multi kriteria menggunakan beberapa kriteria dengan skala dan nilai yang berbeda. Karena setiap data dalam kriteria mempunyai satuan yang berbeda maka perlu dilakukan standarisasi data. Hal ini sesuai penegasan Drobne \& Lisec (2009), bahwa perbedaan skala dan nilai akan mempengaruhi ketepatan hasil analisis apabila tidak dilakukan standarisasi. Skala yang digunakan 1-3. Dimana 1 merupakan lokasi terpilih, 2 jika pilihan alternatif jika 1 tidak ada , dan 3 merupakan lokasi tertolak. Semua variabel eliminator 1-5 dilakukan operasi overlay dan hasilnya dilakukan operasi bersyarat dengan variabel kebutuhan luas minimal, sehingga di temukan kandidat lokasi. Langkah selanjutnya adalah validasi lokasi di lapangan.

Tabel 2. Skoring Kriteria Lokasi pos pemadam (Hasil Anaslisis, 2018)

\begin{tabular}{|c|c|c|}
\hline NO & KRITERIA & SKOR \\
\hline \multirow[t]{4}{*}{1} & Dekat lokasi kerawanan & \\
\hline & 1 Jarak $750 \mathrm{~m}$ & 1 \\
\hline & 2 Jarak $750-1.750$ & 2 \\
\hline & 3 Jarak > $1.750 \mathrm{~m}$ & 3 \\
\hline \multirow[t]{7}{*}{2} & Aksesibilitas & \\
\hline & Jalan Arteri, Kolektor, Lokal primer dengan lebar & \\
\hline & $1 \quad$ Lebar $\geq 6 \mathrm{~m}$ & 1 \\
\hline & 2 Lebar $<6 \mathrm{~m}$ & 3 \\
\hline & Berada ditepi jalan Arteri, kolektor, lokal primer sejauh & \\
\hline & $1 \quad$ Lebar $\leq 75 \mathrm{~m}$ & 1 \\
\hline & 2 Lebar $>75 \mathrm{~m}$ & 3 \\
\hline \multirow[t]{3}{*}{3} & Klasifikasi Desa & \\
\hline & 1 Desa Perkotaan & 1 \\
\hline & 2 Desa Perdesaan & 3 \\
\hline \multirow[t]{4}{*}{4} & Kedekatan Rawan Bencana Banjir & \\
\hline & 1 Bebas Banjir & 1 \\
\hline & 2 Kerawanan Banjir Rendah & 2 \\
\hline & 3 Kerawanan Banjir Sedang - Tinggi & 3 \\
\hline \multirow[t]{3}{*}{5} & Penggunaan Lahan & \\
\hline & 1 Non Build Up Area (Lahan tidak terbangun) & 1 \\
\hline & 2 Build Up Area (Lahan Terbangun) & 3 \\
\hline \multirow[t]{3}{*}{6} & Kebutuhan Luas Lahan & \\
\hline & 1 Luas lahan $\geq 1.000 \mathrm{~m} 2$ & 1 \\
\hline & 2 Luas lahan $<1.000 \mathrm{~m} 2$ & 3 \\
\hline
\end{tabular}

Sumber: Hasil Anaslisis, 2018

\section{HASIL DAN PEMBAHASAN}

3.1. Kerawanan kebakaran di Kabupaten Pati.

Hasil analysis pairwise comparism/ perbandingan berpasangan dalam AHP yang disajikan dalam tabel 3, Jangkauan pelayanan pos pemadam (JPMK) memiliki pengaruh (influence) sangat tinggi, karena semua responden berpendapat bahwa rawan atau tidak suatu kawasan, sangat ditentukan oleh keberadaan lokasi Pos Pemadam Kebakaran. Variabel yang memiliki pengaruh terendah adalah keberadaan sumber air, karena kebanyakan responden menyatakan, adanya Pos pemadam pasti dilengkapi dengan sumber air. Hal ini menunjukkan tentang perlunya peningkatan kapasitas dengan penambahan Pos PMK. 
Tabel 3. Bobot Pairwise Comparism Kriteria Kerawanan Kebakaran (Hasil Analisis, 2018)

\begin{tabular}{|c|c|c|c|c|c|c|c|c|c|c|}
\hline \multirow{2}{*}{ KRITERIA } & \multicolumn{8}{|c|}{ RESPONDEN } & \multirow{2}{*}{$\begin{array}{c}\text { Bobot } \\
\text { Rata-rata }\end{array}$} & \multirow{2}{*}{$\begin{array}{c}\text { Tingkat } \\
\text { Kepentingan }\end{array}$} \\
\hline & 1 & 2 & 3 & 4 & 5 & 6 & 7 & 8 & & \\
\hline $\begin{array}{l}\text { Kepadatan Penduduk } \\
\text { Netto (KPN) }\end{array}$ & 0,20 & 0,13 & 0,19 & 0,13 & 0,18 & 0,15 & 0,17 & 0,13 & 0,16 & 16,00 \\
\hline $\begin{array}{l}\text { Frekuensi Kejadian } \\
\text { Kebakaran (FKK) }\end{array}$ & 0,20 & 1,14 & 0,14 & 0,14 & 0,21 & 0,23 & 0,19 & 0,21 & 0,18 & 18,00 \\
\hline $\begin{array}{lr}\text { Jankauan } & \text { Pos } \\
\text { Pelayanan pos } & \text { PMK } \\
\text { (JPMK) } & \end{array}$ & 0,43 & 0,38 & 0,35 & 0,41 & 0,31 & 0,30 & 0,32 & 0,32 & 0,35 & 35,00 \\
\hline Jaringan Jalan (J) & 0,09 & 0,23 & 0,19 & 0,22 & 0,20 & 0,21 & 0,21 & 0,22 & 0,20 & 20,00 \\
\hline Sumber Air (SA) & 0,08 & 0,11 & 0,12 & 0,10 & 0,09 & 0,11 & 0,11 & 0,13 & 0,11 & 11,00 \\
\hline JUMLAH & & & & & & & & & & 100,00 \\
\hline
\end{tabular}

Sumber: Hasil analisis, 2018

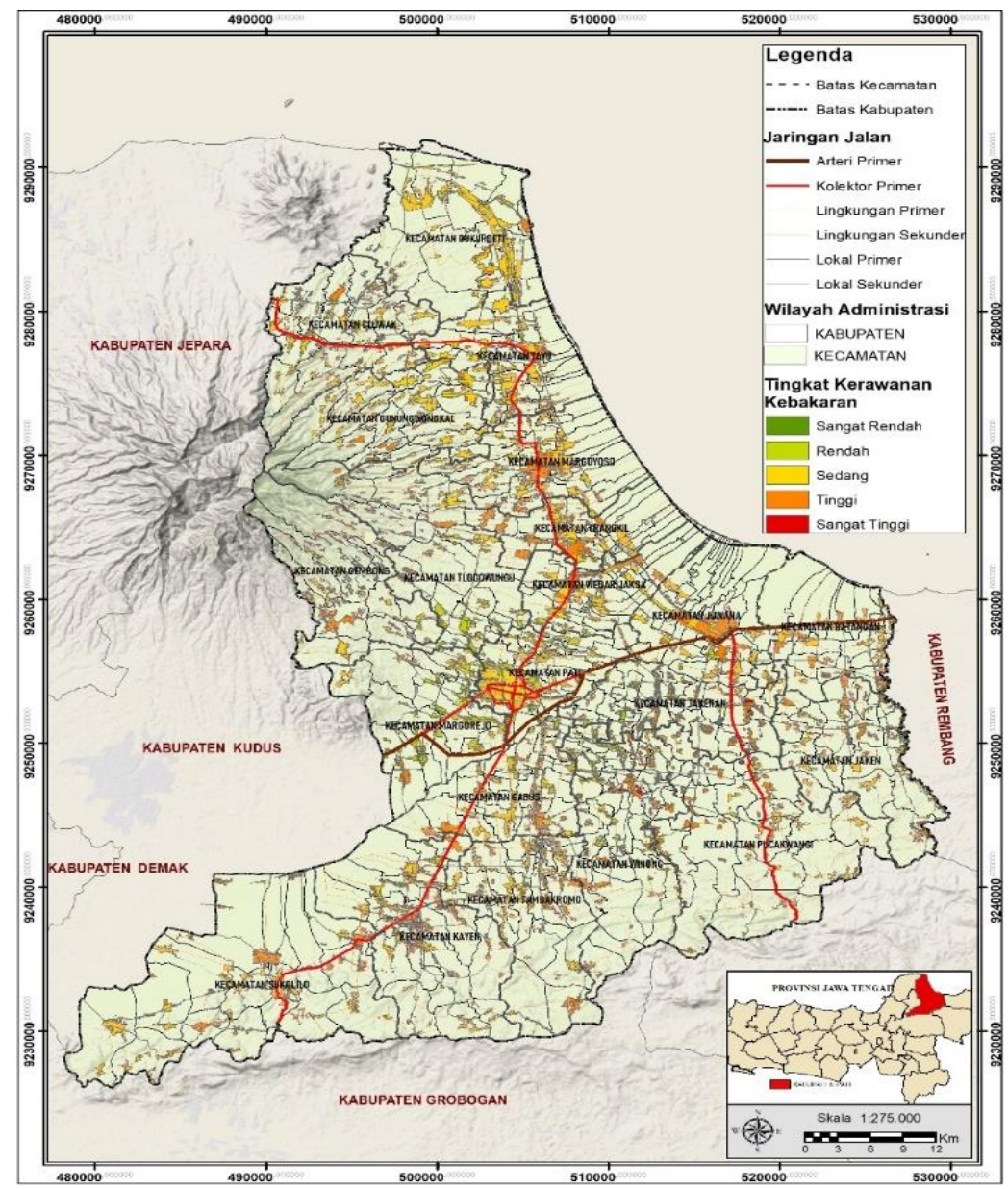

Sumber: Hasil analisis, 2018

Gambar 1. Peta Kerawanan kebakaran di Kabupaten Pati

Pada Gambar 1 berikut, menunjukan terdapat 5 kelas dalam peta potensi kerawanan kebakaran tersebut, yaitu:

1. Tingkat kerawanan kebakaran sangat rendah

Meliputi 8 kecamatan seluas 84,13 ha atau 0,06\% wilayah studi. Dimana luas wilayah perdesaan adalah 57,49 ha dan perkotaan sebesar 26,64 ha. Kecamatan terluasnya adalah kecamatan Pati, dimana semua 
Sugianto, Buchori/ Jurnal Pembangunan Wilayah dan Kota, Vol. 16, No. 1, 2020, 1-11

Doi: $10.14710 /$ pwk.v16i1.19956

desanya masuk dalam jangkauan pos pelayanan PMK dengan luas kerawanan sangat rendah sebesar 26,49 ha.

2. Tingkat kerawanan kebakaran rendah

Meliputi 8 kecamatan seluas 2.805,11 ha. Dimana luas wilayah perdesaan adalah 1.445,94 ha, sedangkan luas perkotaan sebesar 1.359,17 ha . Kecamatan terluasnya adalah kecamatan Pati.

3. Tingkat kerawanan kebakaran sedang

Meliputi 21 kecamatan seluas $11.141,06$ ha atau 7,41\% dari wilayah studi ini. Luas desa perdesaan pada tingkat ini mencapai 7.757,26 ha sedangkan luas potensi kerawanan sedang pada perkotaan sebesar $3.383,80$ ha.

4. Tingkat kerawanan kebakaran tinggi

Meliputi 21 kecamatan dengan 281 desa dan kota seluas $5.141,46$ ha atau 3,42\% wilayah studi. Perbandingan kedua wilayah pada tingkat kerawanan sebesar 70 perkotaan $(36,04 \%)$ dan 211 perdesaan (63,96\%) . Dimana potensi kerawanan tetinggi adalah Juwana seluas 464,17 Ha dan terkecilnya adalah Kecamatan Pati seluas 16,95 ha.

5. Tingkat kerawanan kebakaran sangat tinggi

Meliputi 8 kecamatan dengan 18 desa dan kota seluas 68,68 ha atau 0,05\% dari wilayah studi. Perbandingan kedua wilayah pada tingkat kerawanan sebesar 9 perkotaan $(50,00 \%)$ dan 9 perdesaan (50,00\%). Dimana potensi kerawanan terluasnya adalah kecamatan Winong yaitu 41,87 ha sedangkan terkecilnya adalah Tambakromo sebesar 0,16 ha. Terlihat dalam peta dimana arah persebaran lokasinya ke arah selatan (Kayen, Tambakromo, Winong, Gabus, dan Jakenan), arah barat (Margorejo), ke timur (Juwana) dan Utara (Wedarijaksa).

Dari hasil analisis ini, diketahui bahwa wilayah yang membutuhkan prioritas perlindungan terhadap bahaya kebakaran adalah wilayah dengan tingkat kerawanan tinggi dan sangat tinggi.

3.2. Analisis kebutuhan pos pemadam di kabupaten Pati.

Hasil tahap penyaringan lokasi menunjukkan ada 11 kandidat lokasi pos baru, yaitu di kecamatan Cluwak, Tayu, Margoyoso, Trangkil, Wedarijaksa, Juwana, Batangan, Jakenan, Pucakwangi, Kayen, dan sukolilo. Agar mendapat kandidat lokasi yang paling optimal, maka dilakukan evaluasi lokasi menurut jangkauan area layanan. Seleksi selanjutnya untuk mendapatkan prioritas pembangunan pos pemadam yang baru, dengan mengkomparasi prioritas pembangunan wilayah di kabupaten Pati.

3.2.1. Kebutuhan lokasi pos pemadam berdasarkan area layanan menurut waktu tanggap darurat

Penggunaan waktu tempuh sesuai persyaratan waktu tanggap darurat 15 menit, time rate yang digunakan untuk mensimulasi adalah 5 dan 10 menit, karena sisa waktunya akan digunakan untuk melakukan pemadaman di lapangan. Analisis yang digunakan Network analyst (NA)- service area dalam arcgis, karena mampu mensimulasikan area layanan yang dapat dijangkau kendaraan pemadam menurut kecepatan terpilih dalam tabel 4 yang mengacu standar kecepatan menurut peraturan menteri perhubugan no 111 tahun 2015 dan empiris petugas lapangan sehingga dampak kebakaran dapat ditekan.

Tabel 4. Bobot Pairwise Comparism Kriteria Kerawanan Kebakaran

\begin{tabular}{cllll}
\hline No & Kriteria Jalan & Permenhub no 111/2015 & Petugas PMK & Kecepatan terpilih \\
\hline 1 & Jalan Arteri & $>60 \mathrm{~km} / \mathrm{jam}$ & $80 \mathrm{~km} / \mathrm{jam}$ & $70 \mathrm{~km} / \mathrm{jam}$ \\
2 & Jalan Kolektor & $>40 \mathrm{~km} / \mathrm{jam}$ & $70 \mathrm{~km} / \mathrm{jam}$ & $60 \mathrm{~km} / \mathrm{jam}$ \\
3 & Jalan Lokal & $>40 \mathrm{~km} / \mathrm{jam}$ & $60 \mathrm{~km} / \mathrm{jam}$ & $50 \mathrm{~km} / \mathrm{jam}$ \\
4 & Jalan Lingkungan & $30 \mathrm{~km} / \mathrm{jam}$ & $40 \mathrm{~km} / \mathrm{jam}$ & $35 \mathrm{~km} / \mathrm{jam}$ \\
\hline
\end{tabular}

Sumber: Hasil analisis, 2018 
A. Skenario 1, waktu tempuh 5 menit.

Ini batas waktu terbaik ketika mobil pemadam mampu menjangkau lokasi kebakaran dari pos. Semua Pos pemadam yang ada, baik itu pos eksisting milik pemerintah, 11 kandidat lokasi baru dan 3 pos milik swasta dilakukan analisis NA-services area sehingga di ketahui area layanan masing-masing pos pemadam. Diketahui layanan area pos Trangkil dan wedari jaksa tumpang tindih dengan layanan area milik PT Kebon agung Tangkil. Jadi Kandidat lokasi pembangunan pos baru menjadi 9 lokasi, yaitu kecamatan Cluwak, Tayu, Margoyoso, Juwana, Batangan, Jakenan, Pucakwangi, Kayen dan Sukolilo. Luas area layanan CSR sebesar 68,44 km2, sedangkan 9 lokasi baru sebesar 145,83 km2 dan layanan pos eksisting seluas 23,86 km2.

\section{B. Skenario 2, waktu tempuh 10 menit.}

Diketahui layanan area pos Trangkil dan wedari jaksa tumpang tindih dengan layanan area milik PT Kebon agung Tangkil, sementara layanan area Margoyoso tumpang tindih dengan layanan area milik PT Ladju Perdana Indah Tayu. Jadi Kandidat lokasi pembangunan pos baru menjadi 8 lokasi, yaitu kecamatan Cluwak, Tayu, Juwana, Batangan, Jakenan, Pucakwangi, Kayen dan Sukolilo. Luas area layanan CSR sebesar $268.95 \mathrm{~km} 2$, sedangkan 8 lokasi baru sebesar 446,61 km2 dan layanan pos eksisting seluas 91,59 km2. Disajikan dalam gambar 3 .
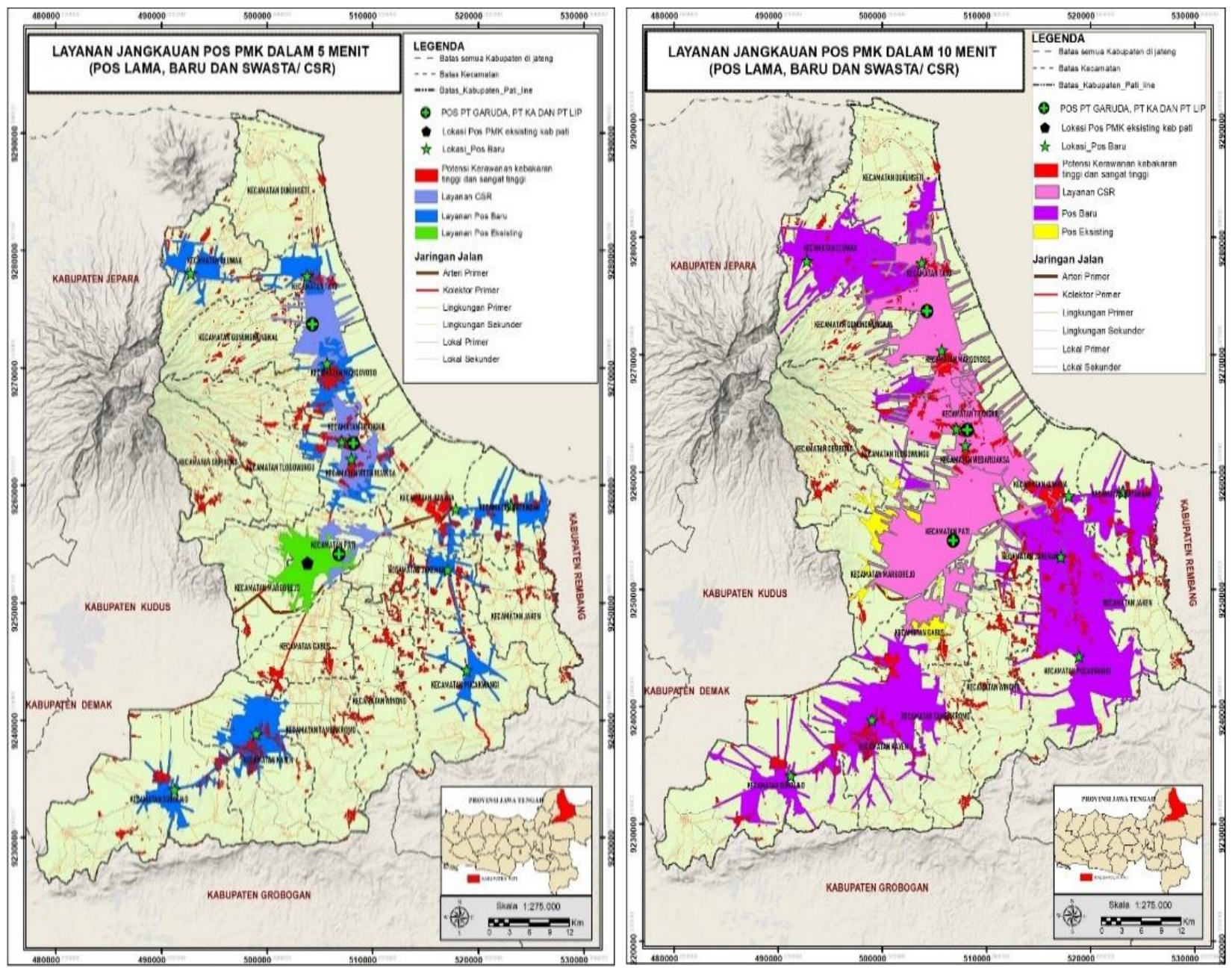

Sumber: Hasil analisis, 2018

Gambar 2. Peta jangkauan layanan area pos pemadam berdasarkan time rate 5 menit dan 10 
Sugianto, Buchori/ Jurnal Pembangunan Wilayah dan Kota, Vol. 16, No. 1, 2020, 1-11

Doi: 10.14710/pwk.v16i1.19956

3.2.2. Kebutuhan lokasi pos pemadam berdasarkan kawasan strategis kabupaten.

Berdasarkan dokumen RTRW kabupaten Pati tahun 2010-2030 dan kawasan strategis kabupaten (KSK) Perkotaan JAKATINATA, ada beberapa kota yang menjadi pusat pengembangan dan pembangunan di kabupaten Pati. Tujuannya adalah mendorong percepatan perekonomian dengan dukungan berbagai sektor yang ada, seperti Perdagangan, jasa, industri, perikanan, perkantoran, dan lain sebagainya. KSK Perkotaan JAKATINATA dibagi menjadi 3 hirarki akan disajikan dalam tabel 5.

Tabel 5. KSK Perkotaan JAKATINATA (Sumber: RTR KSK Perkotaan JAKATINATA, 2017).

\begin{tabular}{cll}
\hline Hirarki & \multicolumn{1}{c}{ Struktur Kota } & \multicolumn{1}{c}{ Kawasan Perkotaan } \\
\hline I & Pusat Kegiatan Lokal (PKL) & 1. Kawasan Strategis Perkotaan Pati \\
& & 2. Kawasan Strategis Perkotaan Juwana \\
& & 3. Kawasan Strategis Perkotaan Tayu \\
II & Pusat Kegiatan Lokal Promosi (PKL-p) & Kawasan Strategis Perkotaan Kayen \\
III & Pusat Pelayanan Kawasan (PPK) & 1. Kawasan Strategis Perkotaan Trangkil \\
& & 2. Kawasan Strategis Perkotaan Jakenan \\
\hline
\end{tabular}

Sumber: RTR KSK Perkotaan JAKATINATA, 2017

Mengacu kepada prioritas perlindungan kebakaran menurut Kementrian Dalam Negeri (2012), selain memiliki kerawanan kebakaran, adanya kawasan kawasan khusus juga menjadi prioritas perlindungan. Jika terjadi gangguan kebakaran pada kawasan ini akan memiliki dampak sosial ekonomi yang besar. Mengacu kepada kebutuhan lokasi berdasarkan area layanan dan prioritas perlindungan terhadap kawasan strategis maka di dapat 6 lokasi pembangunan baru. Yaitu 3 pos pada struktur kota hiraki I (Pati, Juwana, dan Tayu); 1 pos pada Hirarki II (Kayen); 1 pos pada hirarki III (Jakenan) dan trangkil tidak di bangun karena adanya layanan CSR dari PT Kebonagung; dan 2 pos di kawasan penyangga industri, perdagangan, dan permukiman di Batangan dan Sukolilo. Terlihat dalam gambar 4. Kawasan perkotaan JAKATINATA dalam terlindungi menurut waktu tempuh 5 menit.

\section{KESIMPULAN}

Berdasarkan 5 (Lima) kriteria yang digunakan dalam menentukan kerawanan kebakaran. Hasil analisis pairwise comparism dari variabel sebagai berikut JPMK (35\%), JJ (20\%), FKK (18\%), KPN (16\%) dan SA (11\%). Hal ini menunjukkan jika faktor jangkauan pelayanan pos pemadam kebakaran (JPMK) menjadi prioritas paling besar dalam menentukan tingkat kerawanan kebakaran di kabupaten pati. Potensi Kerawanan kebakaran sangat tinggi meliputi 8 kecamatan dengan 18 desa perkotaan dan perdesaan (50\%:50\%) seluas 68,68 ha atau $0,05 \%$ wilayah studi, sedangkan potensi kerawanan tinggi tersebar di 21 kecamatan dengan 281 desa perkotaan dan perdesaan $(36,04 \%: 63,96 \%)$ seluas $5.141,46$ ha atau $3,42 \%$ wilayah studi. Hal tersebut juga mengindikasikan bahwa penambahan pos pemadam baru, sangat penting untuk dilakukan di Kabupaten Pati, dalam rangka memberikan proteksi terhadap bahaya kebakaran. Berdasarkan tahap penyaringan lokasi dengan pendekatan terhadap potensi kerawanan kebakaran, lokasi memiliki aksesibilitas yang baik, lokasi tidak berada di kawasan rawan bencana banjir, lokasi tidak berada pada lahan terbangun serta ketersedian lahan minimal untuk pembangunan pos pmk seluas $1.000 \mathrm{~m} 2$. Menurut hasil evaluasi area layanan pos pemadam baru, dengan melibatkan layanan pos eksisting dan peran serta stakeholder dengan CSRnya menurut waktu tempuh 5 menit ada 9 lokasi pos PMK (Kecamatan Cluwak, Tayu, Margoyoso, Juwana, Batangan, Pucakwangi, Kayen, dan Sukolilo). Berdasarkan waktu tempuh 10 menit ada 8 pos PMK (Kecamatan Cluwak, Tayu, Juwana, Batangan, Pucakwangi, Kayen, dan Sukolilo). Hasil analisis kebutuhan dan lokasi terbaik pos pmk adalah 6 lokasi (Tayu, Juwana, Batangan, Jakenan, Kayen dan Sukolilo) menurut komparisi kebutuhan perlindungan terhadap kawasan strategis kabupaten dan evaluasi terhadap area jangkauan pelayanan menurut time rate yang ditentukan. 


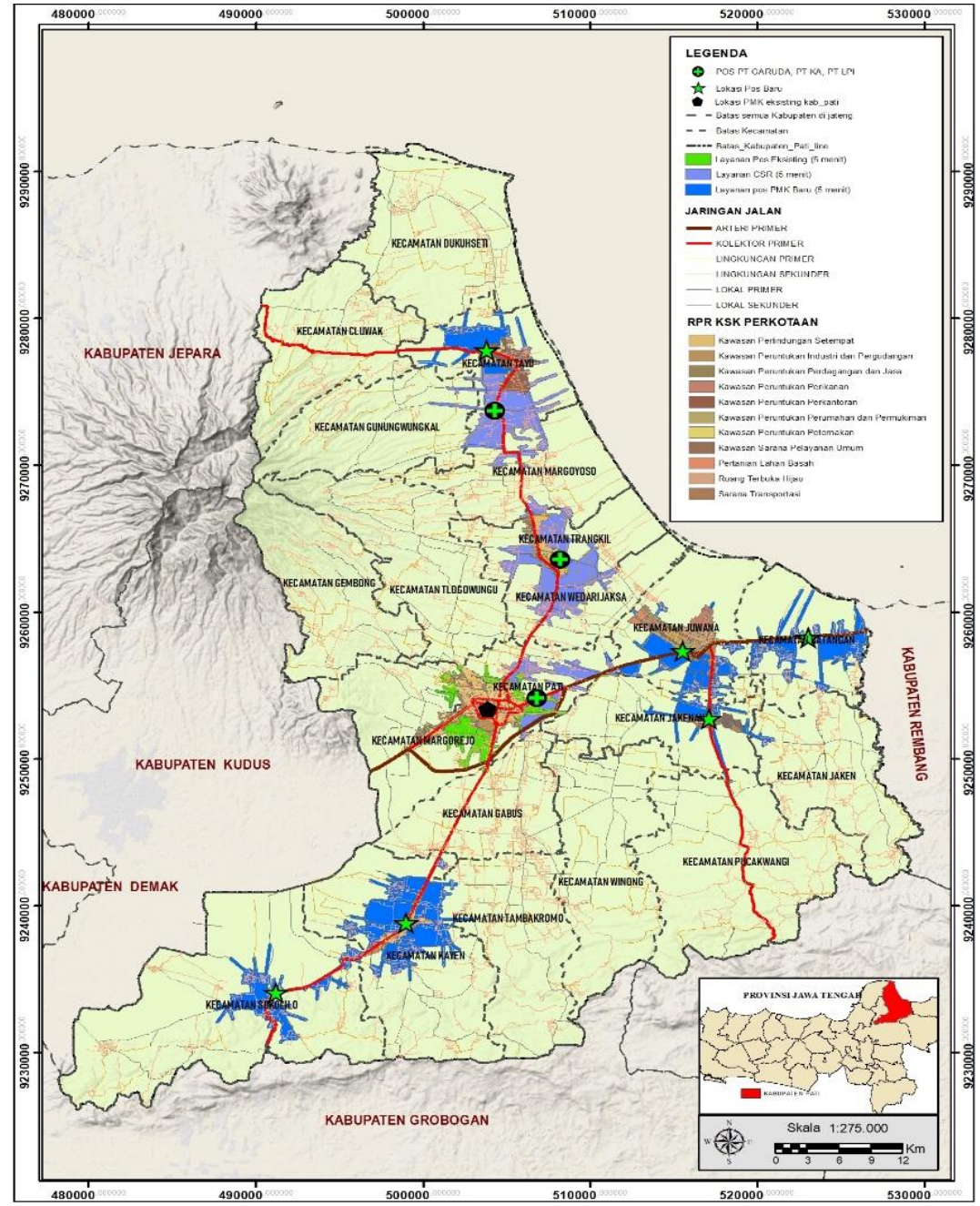

Gambar 3. Peta jangkauan layanan area pos pemadam berdasarkan kawasan strategis kabupaten dan time rate 5 menit

\section{PERNYATAAN RESMI}

Penulis sangat berterimakasih kepada BPSDM Kementrian PUPR serta pemerintah daerah kabupaten Pati atas kesempatan dan dukungan dana penelitian ini.

\section{REFERENSI}

Badri, M. A., Mortagy, A. K., \& Alsayed, C. A. (1998). A multi-objective model for locating fire stations. European Journal of Operational Research, 110(2), 243-260. https://doi.org/10.1016/S0377-2217(97)00247-6

Bagir, M., \& Buchori, I. (2012). Model Optimasi Lokasi Pos Pemadam Kebakaran (Studi Kasus : Kota Semarang). Teknik, 33(1), 12-20. https://doi.org/10.147/teknik.v33i1.3789

BSN. (2004). SNI 03-1733-2004 Tentang Tata cara perencanaan lingkungan perumahan di perkotaan, 1-58.

Chhetri, S., \& Kayastha, P. (2015). Manifestation of an Analytic Hierarchy Process (AHP) Model on Fire Potential Zonation Mapping in Kathmandu Metropolitan City, Nepal. ISPRS International Journal of Geo-Information, 4(1), 400-417. https://doi.org/10.3390/ijgi4010400

Christo, W., \& Weku, D. (2012). Kecenderungan Pemilihan Lokasi Pemukiman Berdasarkan Analisis Multikriteria Di Kota Manado. Ilmiah Sains, 12(2), 142-148.

Dinas Satuan Polisi Pamong Praja. (2017). Laporan Kejadian Kebakaran di Kabupaten Pati Tahun 2012-2017. Pati: Dinas Satpol PP. 
Sugianto, Buchori/ Jurnal Pembangunan Wilayah dan Kota, Vol. 16, No. 1, 2020, 1-11

Doi: $10.14710 /$ pwk.v16i1.19956

Drobne, S., \& Lisec, A. (2009). Multi-attribute Decision Analysis in GIS : Weighted Linear Combination and Ordered Weighted Averaging, 33, 459-474.

Habibi, K., Lotfi, S., \& M.J, K. (2008). Spatial Analysis of Urban Fire Station Locations by Integrating AHP Model and IO Logic Using GIS (A Case Study of Zone 6 of Tehran). Journal of Applied Sciences (Vol. 8). https://doi.org/10.3923/jas.2008.3302.3315

Kabupaten Pati. Peraturan Daerah no 5 tahun 2011 tentang rencana Tata Ruang Wilayah Kabupaten Pati Tahun 20102030.

Kabupaten Pati. Rencana tata ruang kawasan strategis kabupaten JAKATINATA (2017).

Keane, R. E., Drury, S. A., Karau, E. C., Hessburg, P. F., \& Reynolds, K. M. (2010). A method for mapping fire hazard and risk across multiple scales and its application in fire management. Ecological Modelling, 221(1), 2-18. https://doi.org/10.1016/j.ecolmodel.2008.10.022

Kementrian Dalam Negeri. Perubahan atas peraturan Menteri Dalam Negeri no 62 tahun 2008 tentang standar pelayanan minimal bidang pemerintahan dalam negeri di kabupaten/ Kota (2012).

Kementrian Pekerjaan Umum. Pedoman teknis manajemen proteksi kebakaran di perkotaan (2009).

Kementrian Perhubungan RI. Peraturan Menteri Perhubungan Republik Indonesia Nomor 111 Tahun 2015 Tentang tata cara Batas Kecepatan (2015).

Muryamto, R. (2004). Penentuan Daerah Rawan Kebakaran dengan Sistem Informasi Geografik (Kasus Pooncarie Region, New South Wales, Australia), 28(I).

Rikalovic, A., Cosic, I., \& Lazarevic, D. (2014). GIS based multi-criteria analysis for industrial site selection. Procedia Engineering, 69, 1054-1063. https://doi.org/10.1016/j.proeng.2014.03.090

Roig-Tierno, N., Baviera-Puig, A., Buitrago-Vera, J., \& Mas-Verdu, F. (2013). The retail site location decision process using GIS and the analytical hierarchy process. Applied Geography, 40, $191-198$. https://doi.org/10.1016/j.apgeog.2013.03.005

Saaty, T. L. (2008). Decision making with the analytic hierarchy process. International Journal of Services Sciences, 1(1), 83. https://doi.org/10.1504/IJSSCI.2008.017590

Song, J., Zhang, M. G., Zheng, F., \& Chen, F. Z. (2018). Dynamic Simulation of the Group Behavior under Fire Accidents Based on System Dynamics. Procedia Engineering, 211, 635-643. https://doi.org/10.1016/j.proeng.2017.12.058

Srivanit, M. (2011). Community Risk Assessment : Spatial Patterns and GIS-Based Model for Fire Risk Assessment - A Case Study of Chiang Mai Municipality. Jars, 8(2), 113-126.

Wahab, S. D., \& Khayyat, A. H. (2014). Modeling the Suitability Analysis to Establish New Fire Stations in Erbil City Using the Analytic Hierarchy Process and Geographic Information Systems, 2(1), 1-10.

Wei, L., Li, H. L., Liu, Q., Chen, J. Y., \& Cui, Y. J. (2011). Study and implementation of fire sites planning based on GIS and AHP. Procedia Engineering, 11, 486-495. https://doi.org/10.1016/j.proeng.2011.04.687

Yunus, H.S. (2010). Metodologi Penelitian: Wilayah Kontemporer. Yogyakarta: Pustaka Pelajar. 